\title{
Fate of Coiled Aneurysms with Minor Recanalization at 6 Months: Rate of Progression to Further Recanalization and Related Risk Factors
}

\author{
(D).P. Jeon, (D).D. Cho, (D).K. Rhim, (DD.H. Yoo, (D).-S. Cho, (DH.-S. Kang, (DJ.E. Kim, and (D)M.H. Han
}

\begin{abstract}
BACKGROUND AND PURPOSE: Minor recanalization in coiled aneurysms may remain stable with time or may progress to major recanalization. Our aim was to monitor the aneurysms displaying minor recanalization in imaging studies at 6 months, gauging major recanalization rates and related risk factors through extended follow-up.
\end{abstract}

MATERIALS AND METHODS: Sixty-five aneurysms (in 65 patients) showing minor recanalization in follow-up imaging at 6 months were reviewed retrospectively. Medical records and radiologic data accruing during extended monitoring (mean, $24.8 \pm 8.2$ months) were assessed. Univariate and multivariate analyses were conducted to identify risk factors for progression from minor-to-major recanalization.

RESULTS: Progression to major recanalization was observed in 24 (36.9\%) of the initially qualifying aneurysms during a follow-up of 112.5 aneurysm-years, for an annual rate of $17.84 \%$ per aneurysm-year. Progression was determined chronologically as follows: 14 (58.3\%) at 6 months, 8 (33.3\%) at 18 months, and $2(8.4 \%)$ at 30 months. Stent deployment significantly decreased the occurrence of major recanalization $(\mathrm{OR}=0.22, P=.03)$, whereas antiplatelet therapy (OR $=0.82, P=.75)$, posterior location $(\mathrm{OR}=0.24, P=.20)$, and second coiling for recanalized aneurysms $(O R=0.96, P=.96)$ were unrelated.

CONCLUSIONS: Our analysis determined a $36.9 \%$ rate of major recanalization during a follow-up of 112.5 aneurysm-years in coiled aneurysms showing minor recanalization at 6 months. Stent deployment alone conferred a protective effect, preventing further recanalization without additional treatment. Given the fair probability of late major recanalization, aneurysms showing minor recanalization at 6 months should be monitored diligently, particularly in the absence of stent placement.

ABBREVIATIONS: $\mathrm{DM}=$ diabetes mellitus; $\mathrm{HTN}=$ hypertension; $\mathrm{UIA}=$ unruptured intracranial aneurysm; WSS = wall shear stress

$\mathbf{P}$ hysicians are sometimes at a loss in predicting the potential outcomes of coiled aneurysms if minor recanalization is found during follow-up intervals. This is precisely why recanalization rates and related risk factors (based on initial angiographic results) have been addressed in most prior studies. Unfortunately, end points have thus far been measured as all recanalizations (major and minor), ${ }^{1}$ major recanalization only, ${ }^{2}$ or retreatment rates, ${ }^{3}$ leaving a void with respect to the clinical course of aneurysms showing minor recanalization. In general, minor recanalization is not an indication for additional treatment, though progression to

Received November 5, 2015; accepted after revision January 28, 2016.

From the Department of Neurosurgery (J.P.J.), Hallym University College of Medicine, Chuncheon, Korea; and Departments of Radiology (Y.D.C., J.K.R., D.H.Y., M.H.H.) and Neurosurgery (W.s.C., H.-S.K., J.E.K.), Seoul National University College of Medicine, Seoul, Korea.

Please address correspondence to Young Dae Cho, MD, Department of Radiology Seoul National University Hospital, Seoul National University College of Medicine, 28 Yongon-dong, Jongno-gu, Seoul, Korea, 110-744; e-mail: aronnn@empal.com

三 Indicates article with supplemental on-line table.

http://dx.doi.org/10.3174/ajnr.A4763 major recanalization may eventually call for further intervention. Lejeune et $\mathrm{al}^{4}$ described a series of 21 coiled aneurysms subjected to additional surgical treatment for major recanalization (Raymond class 3). Lin et $\mathrm{al}^{5}$ also reported that residual necks of 1-2 $\mathrm{mm}$ may expand to $4-25 \mathrm{~mm}$ during a mean of 9 years. Accordingly, further study of the progression from minor-to-major recanalization is needed to devise proper treatment and management. For this study, we investigated treatment outcomes in aneurysms showing minor recanalization 6 months after coiling, assessing the clinical course, rate of progression to major recanalization, and related risk factors.

\section{MATERIALS AND METHODS}

A retrospective analysis was conducted, reviewing 1035 aneurysms in 898 patients who had undergone coil embolization between January 2008 and December 2010 at Seoul National University Hospital. Nonsaccular aneurysms $(n=70)$ with fusiform shapes or resulting from dissection, trauma, or infection were excluded. In accord with institutional protocol, follow-up radio- 
logic examinations via 3D time-of-flight MR angiography, including source images, were conducted at 6, 12, 18, 24, and 36 months after coil embolization. Conventional angiography was advised if posttreatment MRA was not feasible or if major recanalization of an aneurysm was suspected by noninvasive diagnostics. As stipulated by the Raymond classification, recanalization at 6 months was defined as contrast filling the aneurysm neck (minor recanalization) or dome (major recanalization) at follow-up imaging. ${ }^{2}$ The primary study end point was major recanalization during extended follow-up in coiled aneurysms showing only minor recanalization at 6 months. To categorize extended anatomic outcomes, we applied the Raymond scale as follows: progressive aneurysmal occlusion (no contrast filling within aneurysm), stable stationary state (contrast filling the neck of the aneurysm only, no change relative to the 6-month status), or major recanalization (saccular contrast filling, further recanalization relative to the 6-month status).

Medical records were reviewed for multiple parameters, including sex, age, clinical presentation (unruptured intracranial aneurysm [UIA] or subarachnoid hemorrhage), aneurysmal status (initial or recanalized aneurysm), hypertension (HTN), diabetes mellitus (DM), smoking, and history of antiplatelet therapy. Angiographic variables assessed included the size of the aneurysm and its neck, location (anterior-versus-posterior circulation), ${ }^{6}$ type of aneurysm (sidewall-versus-bifurcation), depth-to-neck ratio, packing density, stent deployment, and type of coil (hydrogelmodified coils [HydroSoft coils; MicroVention, Tustin, California] and polyglycolic acid/lactide copolymer-coated coils [Matrix coils; Stryker, Kalamazoo, Michigan]). According to the length of the bioactive coil used (relative to the total length of the coil inserted), aneurysms were grouped as bare $(\leq 50 \%)$ or bioactive $(>50 \%)$ coils. $^{7}$ This study was approved by the institutional review boards.

\section{Endovascular Procedure and Angiographic Follow-Up}

Most of the endovascular procedures were conducted with the patient under general anesthesia, by using an Integris V (Philips Healthcare, Best, the Netherlands) scanner in each instance. Dual-agent antiplatelet therapy (loading doses of clopidogrel and aspirin [ie, $300 \mathrm{mg}$ each] given 1 day before the procedure, with an additional morning dose of clopidogrel [75 mg] and aspirin [100 mg] on the day of the procedure) was administered if stent protection was anticipated in patients with unruptured aneurysms. ${ }^{8}$ In poor responders to clopidogrel, signaled by VerifyNow P2Y12 assay (Accumetrics, San Diego, California), cilostazol was added. We prescribed single-agent (clopidogrel) therapy if stent placement was not planned, adding aspirin in poor responders. In patients presenting with $\mathrm{SAH}$, antiplatelet medications were withheld. A bolus of heparin (3000 IU), given on placement of the femoral arterial sheath, was thereafter sustained by hourly doses (1000 IU); activated clotting time was monitored each hour. After the procedure, continuance of the dual antiplatelet therapy was advised for at least 3 months postoperatively, followed by singleagent maintenance for at least 1 year in patients with stent deployment. In the absence of a stent, antiplatelet therapy was selectively used for patients with prior antiplatelet medication histories, coil protrusion, and procedural thromboembolism.
Patients were grouped according to immediate angiographic status after coil embolization, by using the Raymond scale, as either successful occlusion (complete occlusion or residual neck) or residual sac. Immediate angiographic results and follow-up diagnoses were interpreted by 2 experienced neurointerventionists (Y.D.C., 8 years' experience; H.-S.K., 13 years' experience). In cases of discrepancy between the reviewers, a consensus was reached by the third interventional neuroradiologist (M.H.H., $>25$ years experience).

\section{Statistics}

Continuous data were presented as the mean \pm SD. A $\chi^{2}$ or Fisher exact test and an unpaired $t$ test were used to assess categoric and continuous variables, respectively. Univariate analysis was applied to evaluate factors pertaining to recanalization after coiling. Risk factors for progression from minor-to-major recanalization were determined by using a logistic regression model to analyze variables with $P$ values $<.20$. The average annual major recanalization transformation rate was calculated as the major recanalization count divided by total aneurysm-years of followup. We used standard software (SPSS, Version 19; IBM, Armonk, New York) for all the above, setting statistical significance at $P<.05$.

\section{RESULTS}

\section{Characteristics of Coiled Aneurysms with Minor Recanalization at 6-Month Follow-Up}

A total of 965 saccular aneurysms were treated by coil embolization between January 2008 and December 2010. After we excluded 66 aneurysms that lacked 6-month postembolization follow-up, including 16 patients in a vegetative state and 10 deaths, 899 aneurysms were initially eligible for the study. Another 34 aneurysms followed for 6 months only were also excluded. Of the remaining 865 aneurysms, 742 were completely occluded at the 6-month point and 58 demonstrated major recanalization. Ultimately, 65 aneurysms in 65 patients ( 48 women, $73.8 \%$; mean age, $57.9 \pm 11.0$ years) qualified for study during a mean extended follow-up of $24.8 \pm 8.2$ months, each showing minor recanalization 6 months after coiling. Most lesions involved the anterior $(56 / 65,86.2 \%)$ rather than posterior $(9 / 65,13.8 \%)$ circulation. In the anterior circulation, the distribution was as follows: internal carotid artery, 16; anterior cerebral artery, including the anterior communicating artery, 21; middle cerebral artery, 9; and posterior communicating artery, 10 . Sidewall and bifurcation aneurysms occurred in $15(23.1 \%)$ and $50(76.9 \%)$ patients, respectively. As an initial angiographic outcome, 54 coiled aneurysms $(83.1 \%)$ were successfully occluded. The mean size of aneurysms was estimated at $6.3 \pm 3.2 \mathrm{~mm}$, with $45(69.2 \%)$ being $\leq 7 \mathrm{~mm}$. Sixteen $(24.6 \%)$ patients presented with SAH. The depth-to-neck ratio was $>1$ in 38 aneurysms $(58.5 \%)$. HydroSoft and Matrix coils were used for 26 and 6 subjects, respectively. The bioactive coil group (length of bioactive coil used [relative-to-total length of the coil inserted] $>50 \%$ ) included 20 coils $(30.8 \%)$, and all were HydroSoft. Stents were present in 19 patients (29.2\%): Enterprise (Codman \& Shurtleff, Raynham, Massachusetts) in 17 and Neuroform (Stryker Neurovascular) in 2. A single stent was used in 18 patients, while double stents were used in 1 patient. 
Table 1: Demographic and angiographic characteristics of coiled aneurysms showing minor recanalization in follow-up images at 6 months $(N=65)$

\begin{tabular}{|c|c|c|c|}
\hline Variables & Stationary $(n=41)$ & Major Recanalization $(n=24)$ & $P$ Value $^{\mathrm{a}}$ \\
\hline \multicolumn{4}{|l|}{ Clinical } \\
\hline Female & 30 (73.2\%) & 18 (75.0\%) & .87 \\
\hline Age (yr) & $58.1 \pm 12.0$ & $57.6 \pm 9.2$ & .86 \\
\hline HTN & $27(65.9 \%)$ & $12(50.0 \%)$ & .21 \\
\hline DM & $3(7.3 \%)$ & $0(0 \%)$ & .29 \\
\hline Hyperlipidemia & $4(9.8 \%)$ & $2(8.3 \%)$ & 1.00 \\
\hline Smoking & $4(9.8 \%)$ & $5(20.8 \%)$ & .21 \\
\hline \multicolumn{4}{|l|}{ Aneurysmal } \\
\hline \multicolumn{4}{|l|}{ Location } \\
\hline Anterior & $33(80.5 \%)$ & $23(95.8 \%)$ & \\
\hline Posterior & $8(19.5 \%)$ & $1(4.2 \%)$ & .08 \\
\hline \multicolumn{4}{|l|}{ Presentation } \\
\hline UIA & $33(80.5 \%)$ & $16(66.7 \%)$ & \\
\hline SAH & $8(19.5 \%)$ & $8(33.3 \%)$ & .21 \\
\hline \multicolumn{4}{|l|}{ Status } \\
\hline Initial & $28(68.3 \%)$ & $20(83.3 \%)$ & \\
\hline Recanalized (2nd coiling) & $13(31.7 \%)$ & $4(16.7 \%)$ & .18 \\
\hline Bifurcation aneurysm & $31(75.6 \%)$ & $19(79.2 \%)$ & .74 \\
\hline Maximum size (mm) & $6.3 \pm 2.7$ & $6.2 \pm 4.1$ & .93 \\
\hline $\mathrm{D} / \mathrm{N}$ ratio $(>1)$ & 22 (53.7\%) & $16(66.7 \%)$ & .30 \\
\hline Neck size (mm) & $4.7 \pm 2.1$ & $4.0 \pm 1.6$ & .22 \\
\hline \multicolumn{4}{|l|}{ Procedural } \\
\hline Stent & $16(39.0 \%)$ & $3(12.5 \%)$ & .02 \\
\hline Balloon & $4(9.8 \%)$ & $4(16.7 \%)$ & .41 \\
\hline Bioactive coil (>50\%) & $13(31.7 \%)$ & $7(29.2 \%)$ & .83 \\
\hline Initial occlusion & & & .47 \\
\hline Successful occlusion & $33(80.5 \%)$ & $21(87.5 \%)$ & \\
\hline Residual sac & $8(19.5 \%)$ & $3(12.5 \%)$ & \\
\hline Antiplatelet maintenance & $25(61.0 \%)$ & $10(41.7 \%)$ & .13 \\
\hline
\end{tabular}

Note:-D/N indicates depth-to-neck.

a $P<.05$ is significant.

Table 2: Logistic regression model assessing the risk of progression to major recanalization in coiled aneurysms showing minor recanalization at 6 months $(N=65)$

\begin{tabular}{lccc}
\multicolumn{1}{c}{ Variables } & \multicolumn{3}{c}{$95 \%$ Confidence } \\
Ontiplatelet maintenance & 0.82 & $0.25-2.68$ & .75 \\
Posterior location & 0.24 & $0.03-2.15$ & .20 \\
Recanalized aneurysm & 0.96 & $0.22-4.30$ & .96 \\
Stent & 0.22 & $0.06-0.87$ & .03 \\
\hline
\end{tabular}

a $P<.05$ is significant.

Rates of HTN, smoking, and antiplatelet therapy were $60.0 \%$ (39/65), 13.8\% (9/65), and 53.8\% (35/65), respectively. Characteristics of aneurysms that qualified for the study are detailed in the On-line Table.

\section{Morphologic Changes to Major Recanalization in Coiled Aneurysms with Minor Recanalization at 6 Months}

Overall, 24 (36.9\%) coiled aneurysms with minor recanalization at 6 months progressed to major recanalization during 112.5 aneurysm-years of follow-up, whereas none had become occluded. No instances of bleeding occurred during the follow-up. The chronology of change from minor-to-major recanalization was as follows: $14(58.3 \%)$ at 6 months, $8(33.3 \%)$ at 18 months, and 2 $(8.4 \%)$ at 30 months. Acquired major recurrences had the following characteristics: women, $75.0 \%(18 / 24)$; age, $57.6 \pm 9.2$ years; anterior location, $95.8 \%$ (23/24); SAH presentation, $33.3 \%$ (8/24); bifurcation type, 79.2\% (19/24); aneurysm size, $6.2 \pm 4.1$ $\mathrm{mm}$; neck size, $4.0 \pm 1.6 \mathrm{~mm}$, HydroSoft coils of $>50 \%, 29.2 \%$ (7/24); depth-to-neck ratio of $>1,66.7 \%$ (16/24); stent deploy- ment, $12.5 \%$ (3/24); second coiling for recanalized aneurysms, $16.7 \%(4 / 24)$; and antiplatelet therapy, $41.7 \%$ (10/24). Univariate analysis indicated an association between the presence of a stent and morphologic change to major recanalization $(P=.02)$. Other variables, such as SAH presentation $(P=.21)$, bifurcation type $(P=.74)$, second coiling for recanalized aneurysms $(P=.18)$, antiplatelet therapy $(P=.13)$, use of a balloon $(P=.41)$, residual sac as an immediate postembolization finding $(P=.47)$, and depth-to-neck ratio $>1$ $(P=.30)$, were unrelated to a change in recanalization status (Table 1 ). Binary logistic regression analyses underscored the protective effect of stent placement on transformation to major recanalization $(\mathrm{OR}=0.22 ; 95 \% \mathrm{CI}, 0.06-0.87$; $P=.03)$, whereas other variables, including antiplatelet therapy $(\mathrm{OR}=0.82$; 95\% CI, 0.25-2.68; $P=.75)$, posterior location $(\mathrm{OR}=0.24 ; 95 \% \mathrm{CI}, 0.03-2.15$; $P=.20)$, and second coiling for recanalized aneurysms $(\mathrm{OR}=0.96 ; 95 \% \mathrm{CI}$, $0.22-4.30 ; P=.96)$, had no bearing on observed transformation to major recanalization (Table 2).

The overall annual rate of major recanalization in coiled aneurysms with minor recanalization at 6-month follow-up was $17.84 \%$ per aneurysm-year. The rate of change from minor-to-major recanalization was $7.79 \%$ per year in instances of stent deployment, as opposed to $16.67 \%$ without stent placement. With the Kaplan-Meier method, estimated cumulative survival at 30 months in the absence of major recanalization with and without stent deployment was $81.3 \%$ versus 47.4\% $(P=.07)$.

\section{DISCUSSION}

Minor recanalization in aneurysms may remain stable with time or may progress to major recanalization. To our knowledge, accurate information on the likelihood of transforming from minor-to-major recanalization has been lacking. In our analyses, $36.9 \%$ of coiled aneurysms displaying minor recanalization at 6 months progressed to major recanalization during a follow-up of 112.5 aneurysm-years, for an overall annual rate of $17.84 \%$ per aneurysm-year.

Previous studies have reported variable rates $(10.7 \%-33.6 \%)$ of overall recanalization in coiled aneurysms, with major recanalization ranging from $3.9 \%$ to $20.7 \%{ }^{1,2}$ The propensity for recanalization in aneurysms is known to be a factor of presentation (SAH versus UIA), aneurysm size, and initial therapeutic results. ${ }^{3}$ Ruptured (versus nonruptured) aneurysms are more likely to recanalize. ${ }^{2,9}$ Spontaneous clot lysis at rupture points or thrombus within the sac may contribute to a higher coil compaction in patients presenting with $\mathrm{SAH},{ }^{9}$ which is the aim of interventionists. Sluzewski et $\mathrm{al}^{10}$ reported that coiled aneurysms with volumes of 
$<600 \mathrm{~mm}^{3}$ did not undergo recanalization at packing densities of $>24 \%$. Morales et $\mathrm{al}^{11}$ also showed that intra-aneurysmal hemodynamics, such as blood flow velocity and wall shear stress (WSS), may be reduced by increasing packing attenuation to near $30 \%$. In our institution, we have tried to obtain high packing density and achieve anatomically complete occlusion regardless of presentation. In particular, complete occlusion is mandatory in ruptured aneurysms. As a result of the effort, the mean coil packing density was $32.1 \% \pm 9.2 \%$, and the difference noted in subset packing densities was not significant according to presentation (UIA, $30.8 \pm 7.2 \%$; SAH, $34.9 \pm 12.1 \% ; P=.15$ ), except in 17 reembolized aneurysms (where estimating packing attenuation was not feasible).

Migration of a coil into the thrombus may also lead to major recanalization with time. ${ }^{12}$ However, saccular thrombus is more easily detected in larger-sized aneurysms than in smaller ones. The aneurysm size did not differ significantly according to the presentation (SAH, $6.0 \pm 2.6 \mathrm{~mm}$; UIA, $6.4 \pm 3.4 \mathrm{~mm}$; $P=.66$ ) in our cohort. Thus, we speculate that the relatively small-sized aneurysms and the higher packing densities of this cohort may be responsible for the lack of a significant correlation between SAH presentation and the rate of progression to major recanalization.

In a study by Cognard et al, ${ }^{9}$ a clinical correlation between aneurysm size and recanalization rate $(2-3 \mathrm{~mm}, 8.7 \%$; $4-5 \mathrm{~mm}$, $9.0 \% ; 6-8 \mathrm{~mm}, 22.0 \%$ ) was found. The aneurysm size of $>10$ $\mathrm{mm}$ has been considered a risk factor for future recanalization. ${ }^{13-15}$ Niimi et al $^{13}$ also reported that $82 \%$ (9/11) of recanalization events occurred in larger aneurysms ( $\geq 10 \mathrm{~mm})$. Hetts et $\mathrm{al}^{14}$ investigated outcomes of coiling with and without stent replacement (Neuroform stent) in unruptured aneurysms in the Matrix and Platinum Science Trial. In their study, aneurysm size of $\geq 10 \mathrm{~mm}$ was associated with target aneurysm recurrence, which was defined as aneurysm rupture after treatment, retreatment, or death from an unknown cause. McDougall et $\mathrm{al}^{15}$ also assessed target aneurysm recurrence at $12 \pm 3$ months according to coil types (Matrix ${ }^{2}$ versus bare metal). Target aneurysm recurrence was associated with incomplete occlusion, ruptured state, and larger aneurysm of $\geq 10 \mathrm{~mm}$. Mean aneurysm size in this investigation was $6.3 \pm 3.2 \mathrm{~mm}$. The size did not differ significantly between the stable stationary group and the major recanalization group (stably stationary, $6.3 \pm 2.7 \mathrm{~mm}$, versus major recanalization, $6.2 \pm 4.1 \mathrm{~mm} ; P=.93)$. Five cases $(7.7 \%)$ with minor recanalization at 6 months after coiling were large aneurysms of $>10 \mathrm{~mm}$. Two (40.0\%) of 5 large aneurysms and 22 $(36.7 \%)$ of 60 small aneurysms $(<10 \mathrm{~mm})$ showed major recanalization, respectively $(P=1.00)$. Therefore, we speculate that our results could be more appropriate for clinical evaluation of smallsized aneurysms with minor recanalization at 6-month follow-up imaging.

The initial therapeutic result is another reputed risk factor for future recanalization. Ries et $\mathrm{al}^{3}$ showed that signs of a residual aneurysm immediately after endovascular treatment significantly increased the risk of recanalization, compared with completely occluded lesions ( $\mathrm{OR}=3.96, P=.006)$. However, projected recanalization rates of completely occluded coiled aneurysms and aneurysms with neck remnants after coiling were similar. In this study, initial angiographic results were stratified as successful oc- clusion (complete occlusion or residual neck) or residual sac. The higher rate of recanalization found in aneurysms showing minor recanalization 6 months after initial successful occlusion (versus residual sac) was not statistically significant (38.9\% versus $27.3 \%$, $P=.47)$. Recently, Ogilvy et $\mathrm{al}^{16}$ devised a reliable recanalization stratification scale for projecting recanalization based on aneurysm-specific variables, initial occlusion status, and treatmentrelated factors. Aneurysm-specific variables, such as a size of $>10$ $\mathrm{mm}$, ruptured state/presence of thrombus, and residual aneurysm (Raymond score of 3), are each awarded 2 points. As treatment-related factors, use of coils only, stent assistance, and flow diverter use earned $0,-1$, and -2 points, respectively. If sums of individual scores were $\geq 5$, the probability of retreatment was high (recanalization of $>73.2 \%$ ). Nevertheless, these results may not fully reflect the impact of risk factors, such as larger size, SAH presentation, and incomplete occlusion, on the progression from minor-to-major recanalization. Timing and duration of follow-up must be considered. Major recanalization largely emerged during the 12 months after embolization. In particular, $46.9 \%$ of all recanalizations ( $40 \%$ of which were major) were detected within the first 6 months of follow-up. ${ }^{2}$ For our purposes, only aneurysms showing minor recanalization 6 months after coiling were studied. Subjects were also monitored diligently during a mean extended follow-up of $24.8 \pm 8.2$ months.

Raymond et $\mathrm{al}^{2}$ previously examined recanalization risk factors relative to the length of follow-up ( $<17$ months versus 17-37 months versus $>37$ months). In patients followed for $<17$ months, the initial therapeutic result was the sole variable associated with recanalization; whereas in patients followed for 17-37 months, aneurysm and neck sizes and initial therapeutic results constituted risk factors. In patients followed for $>37$ months, aneurysm and neck sizes and SAH presentation were associated with recanalization. These results imply that recanalization developing longer term is dependent on inherent risk factors, with incomplete therapeutic occlusion primarily responsible in the short term. Hence, we thought that differing characteristics of subjects in our cohort, such as minor recanalization at 6 months, the relatively longer extended follow-up, and the stipulated study end point (minor to major recanalization), might explain the lack of significant correlation evident between risk factors established elsewhere and progression to major recanalization.

The association between aneurysm location and recanalization remains controversial. Raymond et $\mathrm{al}^{2}$ showed that recanalization rates at various sites (basilar bifurcation, 39.4\%; MCA bifurcation, $32.1 \%$; posterior communicating artery, 37.2\%) did not differ substantially. On the other hand, Kwon et al ${ }^{1}$ determined higher recanalization rates in coiled aneurysms of the posterior circulation and MCA due to technical difficulties. However, on the basis of study end point differences (all recanalization, major and minor) and selection bias (due to stent placement), the previous studies $^{1,2}$ failed to accurately depict the clinical correlation between aneurysm location and minor-to-major progressive recanalization. In our subjects, the rate of transformation to major recanalization was more pronounced in the anterior circulation (overall: 23/56, 41.1\%; ICA: 5/16, 31.3\%; anterior cerebral artery: $10 / 21,47.6 \%$; MCA: $2 / 9,22.2 \%$; posterior communicating artery: $6 / 10,60 \%)$ than in the posterior circulation $(1 / 9,11.1 \%)$. 
Rates of stent deployment differed by location, approaching statistical significance (anterior circulation: 14/56, 25.0\% [ICA, 5; anterior cerebral artery, 5; MCA, 4; posterior communicating artery, 0]; posterior circulation: $5 / 9,55.6 \% ; P=.08$ ). These differing rates of stent deployment may explain the relatively higher proportion of major recanalization events in the anterior circulation.

Hemodynamic forces are thought to figure prominently in aneurysms that recanalize. Luo et $\mathrm{al}^{17}$ have indicated that high WSS and flow velocity, both observed near remnant necks, likely prompt recanalization in coiled aneurysms if occlusion is subtotal. In patients with treated aneurysms that were stable, WSS and blood flow velocity near neck remnants after embolization were lower in $83.3 \%$ (5/6). Irie et $\mathrm{al}^{18}$ similarly confirmed that areas at neck remnants, subject to higher WSS and flow velocity, corresponded with recanalization in coiled aneurysms showing subtotal occlusion. Higher postembolization WSS at aneurysm necks may predispose to recanalization in totally occluded aneurysms as well, ${ }^{19}$ as indicated by higher maximum WSS and spatially averaged WSS in recanalized aneurysms at systole (relative to pretreatment status) and a relative decrease in WSS by $70 \%-80 \%$ in nonrecanalized counterparts. Indeed, elevated WSS due to repetitive flow impingement may encourage recanalization of aneurysms.

Ortega et $\mathrm{al}^{20}$ have documented that blood flow near remnant necks increases maximum WSS by approximately $50 \mathrm{~Pa}$ at systole in basilar tip aneurysms. In clinical practice, stents have been used in anticipation of diverting flow and promoting endothelialization at aneurysm necks, while also achieving higher coil-packing densities. $^{21,22}$ Recanalization rates in the range of $6.6 \%-13 \%$ have been reported after stent-assisted coil embolization. ${ }^{23,24}$ Cho et $\mathrm{al}^{25}$ have also shown that stent implantation reduced recanalization rates 6 months after coiling (stented, 1.9\%; nonstented, $10.2 \%$ ) and at final follow-up (stented, 8.3\%; nonstented, 18.5\%). With respect to recanalized aneurysms, stent placement likewise reduced the major recanalization rate 6 months after retreatment $(\mathrm{OR}=0.16 ; P=.01) .{ }^{26}$ Still, the ability to prevent further recanalization (from minor to major) through stent deployment has yet to be clearly demonstrated. Our study indicates that stent placement does help prevent progression from minor-to-major recanalization $(\mathrm{OR}=0.22 ; P=.03)$, and this benefit is conferred long term, past the 6-month follow-up point.

Although some physicians find a 6-month determination of clinical course adequate in coiled aneurysms with minor recanalization, the durability of coiled aneurysms is a major concern due to relatively high recanalization rates $(10.7 \%-33.6 \%) .{ }^{1,2}$ Given that $46.9 \%$ of recanalization events take place in the first 6 months after embolization, ${ }^{2}$ follow-up imaging is generally initiated within 6 months. However, the fate of aneurysms showing minor recanalization in the first follow-up images is often difficult to predict. Although treatment outcomes, including recanalization rates and related risk factors, have been well-described, potential transformation from minor-to-major recanalization may be a separate issue in terms of providing appropriate information and planning further follow-up. For this study, we have focused on the fate of aneurysms showing minor recanalization at 6-month follow-up, investigating a sizeable sampling (65 qualifying lesions) through strict patient monitoring. Consequently, the outcomes are likely valid. Nevertheless, there are concerns of possible selection bias, based on retrospective design and extent of stent deployment. Although, TOF MRA can be helpful in estimating the degree of recanalization, stent artifacts obscuring minor recanalization could occur. ${ }^{27-30}$ Moreover, the mean aneurysm size in our subjects was estimated at $6.3 \pm 3.2 \mathrm{~mm}$. In Korea, coiled aneurysms $\leq 10 \mathrm{~mm}$ account for $89.3 \%$ of lesions in a national cohort of unruptured aneurysms. ${ }^{1}$ As such, the fate of larger aneurysms $(>10 \mathrm{~mm})$ in this setting may differ.

\section{CONCLUSIONS}

In this study, a $36.9 \%$ rate of progression to major recanalization was determined in coiled aneurysms showing minor recanalization at 6 months. The cohort was followed for 112.5 aneurysmyears, yielding an annual transformation rate of $17.84 \%$ per aneurysm-year. The presence of a stent was the only variable analyzed that conferred a protective effect, preventing progression to major recanalization. The finding of minor recanalization at 6 months, especially in the absence of stent placement, is cause for continued monitoring of coiled aneurysms, due to a fair risk of late major recanalization.

\section{ACKNOWLEDGMENTS}

We thank Sung-Eun Kim for her help with the data collection and statistical support.

Disclosures: Moon Hee Han—UNRELATED: Consultancy: MicroVention.* *Money paid to the institution.

\section{REFERENCES}

1. Kwon SC, Kwon OK; Korean Unruptured Cerebral Aneurysm Coiling (KUCAC) Investigators. Endovascular coil embolization of unruptured intracranial aneurysms: a Korean multicenter study. Acta Neurochir (Wien) 2014;156:847-54 CrossRef Medline

2. Raymond J, Guilbert F, Weill A, et al. Long-term angiographic recurrences after selective endovascular treatment of aneurysms with detachable coils. Stroke 2003;34:1398-403 CrossRef Medline

3. Ries T, Siemonsen S, Thomalla G, et al. Long-term follow-up of cerebral aneurysms after endovascular therapy-prediction and outcome of retreatment. AJNR Am J Neuroradiol 2007;28:1755-61 CrossRef Medline

4. Lejeune JP, Thines L, Taschner C, et al. Neurosurgical treatment for aneurysm remnants or recurrences after coil occlusion. Neurosurgery 2008;63:684-91; discussion 691-92 CrossRef Medline

5. Lin T, Fox AJ, Drake CG. Regrowth of aneurysm sacs from residual neck following aneurysm clipping. J Neurosurg 1989;70:556-60 CrossRef Medline

6. Cho YD, Jeon JP, Rhim JK, et al. Progressive thrombosis of small saccular aneurysms filled with contrast immediately after coil embolization: analysis of related factors and long-term follow-up. Neuroradiology 2015;57:615-23 CrossRef Medline

7. White PM, Lewis SC, Nahser H, et al; HELPS Trial Collaboration. HydroCoil Endovascular Aneurysm Occlusion and Packing Study (HELPS trial): procedural safety and operator-assessed efficacy results. AJNR Am J Neuroradiol 2008;29:217-23 CrossRef Medline

8. Cho YD, Lee WJ, Kim KM, et al. Stent-assisted coil embolization of posterior communicating artery aneurysms. AJNR Am J Neuroradiol 2013;34:2171-76 CrossRef Medline

9. Cognard C, Weill A, Spelle L, et al. Long-term angiographic follow-up of 169 intracranial berry aneurysms occluded with detachable coils. Radiology 1999;212:348-56 CrossRef Medline 
10. Sluzewski M, van Rooij WJ, Slob MJ, et al. Relation between aneurysm volume, packing, and compaction in 145 cerebral aneurysms treated with coils. Radiology 2004;231:653-58 CrossRef Medline

11. Morales HG, Kim M, Vivas EE, et al. How do coil configuration and packing density influence intra-aneurysmal hemodynamics? AJNR Am J Neuroradiol 2011;32:1935-41 CrossRef Medline

12. van Rooij WJ, Sprengers ME, Sluzewski M, et al. Intracranial aneurysms that repeatedly reopen over time after coiling: imaging characteristics and treatment outcome. Neuroradiology 2007;49:343-49 CrossRef Medline

13. Niimi Y, Song J, Madrid M, et al. Endosaccular treatment of intracranial aneurysms using Matrix coils: early experience and midterm follow-up. Stroke 2006;37:1028-32 CrossRef Medline

14. Hetts SW, Turk A, English JD, et al; Matrix and Platinum Science Trial Investigators. Stent-assisted coiling versus coiling alone in unruptured intracranial aneurysms in the Matrix and Platinum Science trial: safety, efficacy, and mid-term outcomes. AJNR Am JNeuroradiol 2014;35:698-705 CrossRef Medline

15. McDougall CG, Johnston SC, Gholkar A, et al; MAPS Investigators. Bioactive versus bare platinum coils in the treatment of intracranial aneurysms: the MAPS (Matrix and Platinum Science) trial. AJNR Am J Neuroradiol 2014;35:935-42 CrossRef Medline

16. Ogilvy CS, Chua MH, Fusco MR, et al. Validation of a system to predict recanalization after endovascular treatment of intracranial aneurysms. Neurosurgery 2015;77:168-73; discussion 173-74 CrossRef Medline

17. Luo B, Yang X, Wang S, et al. High shear stress and flow velocity in partially occluded aneurysms prone to recanalization. Stroke 2011; 42:745-53 CrossRef Medline

18. Irie K, Anzai H, Kojima M, et al. Computational fluid dynamic analysis following recurrence of cerebral aneurysm after coil embolization. Asian J Neurosurg 2012;7:109-15 CrossRef Medline

19. Li C, Wang S, Chen J, et al. Influence of hemodynamics on recanalization of totally occluded intracranial aneurysms: a patient-specific computational fluid dynamic simulation study. J Neurosurg 2012;117:276-83 CrossRef Medline

20. Ortega J, Hartman J, Rodriguez J, et al. Post-treatment hemodynam- ics of a basilar aneurysm and bifurcation. Ann Biomed Eng 2008;36: 1531-46 CrossRef Medline

21. Lawson MF, Newman WC, Chi YY, et al. Stent-associated flow remodeling causes further occlusion of incompletely coiled aneurysms. Neurosurgery 2011;69:598-603; discussion 603-04 CrossRef Medline

22. Chalouhi N, Jabbour P, Singhal S, et al. Stent-assisted coiling of intracranial aneurysms: predictors of complications, recanalization, and outcome in 508 cases. Stroke 2013;44:1348-53 CrossRef Medline

23. Hwang SK, Hwang G, Bang JS, et al. Endovascular Enterprise stentassisted coil embolization for wide-necked unruptured intracranial aneurysms. J Clin Neurosci 2013;20:1276-79 CrossRef Medline

24. Luo CB, Teng MM, Chang FC, et al. Stent-assisted coil embolization of intracranial aneurysms: a single center experience. J Chin Med Assoc 2012;75:322-28 CrossRef Medline

25. Cho WS, Hong HS, Kang HS, et al. Stability of cerebral aneurysms after stent-assisted coil embolization: a propensity score-matched analysis. Neurosurgery 2015;77: 208-16; discussion 216-17 CrossRef Medline

26. Cho YD, Lee JY, Seo JH, et al. Does stent implantation improve the result of repeat embolization in recanalized aneurysms? Neurosurgery 2012;71(2 suppl operative):ons253-59; discussion ons259 CrossRef Medline

27. Jeon JP, Cho YD, Rhim JK, et al. Effect of stenting on progressive occlusion of small unruptured saccular intracranial aneurysms with residual sac immediately after coil embolization: a propensity score analysis. J Neurointerv Surg 2015 Oct 27. [Epub ahead of print] CrossRef Medline

28. Cho YD, Kim KM, Lee WJ, et al. Time-of-flight magnetic resonance angiography for follow-up of coil embolization with Enterprise stent for intracranial aneurysm: usefulness of source images. Korean J Radiol 2014;15:161-68 CrossRef Medline

29. Choi JW, Roh HG, Moon WJ, et al. Optimization of MR parameters of 3D TOF-MRA for various intracranial stents at 3.0T MRI. Neurointervention 2011;6:71-77 CrossRef Medline

30. van Amerongen MJ, Boogaarts HD, de Vries J, et al. MRA versus DSA for follow-up of coiled intracranial aneurysms: a meta-analysis. AJNR Am J Neuroradiol 2014;35:1655-61 CrossRef Medline 